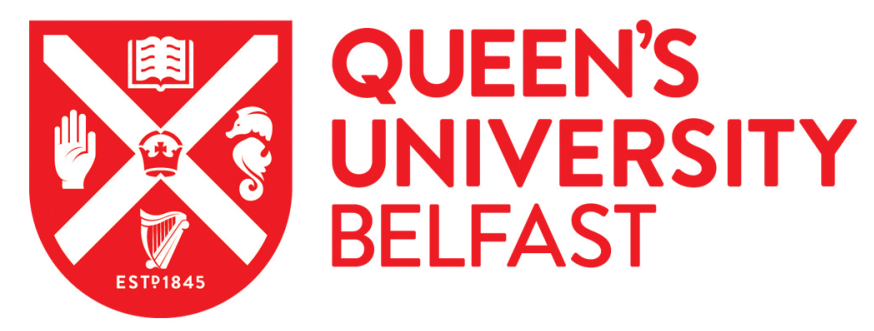

\title{
Preparing for the future: challenges and opportunities for management and leadership skills
}

Morison, S., \& McMullan, C. (2013). Preparing for the future: challenges and opportunities for management and leadership skills. British Dental Journal, 214(1), [E2]. https://doi.org/10.1038/sj.bdj.2012.1177

Published in:

British Dental Journal

Document Version:

Early version, also known as pre-print

Queen's University Belfast - Research Portal:

Link to publication record in Queen's University Belfast Research Portal

Publisher rights

(C) 2013 Macmillan Publishers Limited.

\section{General rights}

Copyright for the publications made accessible via the Queen's University Belfast Research Portal is retained by the author(s) and / or other copyright owners and it is a condition of accessing these publications that users recognise and abide by the legal requirements associated with these rights.

Take down policy

The Research Portal is Queen's institutional repository that provides access to Queen's research output. Every effort has been made to ensure that content in the Research Portal does not infringe any person's rights, or applicable UK laws. If you discover content in the Research Portal that you believe breaches copyright or violates any law, please contact openaccess@qub.ac.uk. 
Preparing for the future: challenges and opportunities for management and leadership skills

Dr Susan Morison, Director, Centre for Excellence in Interprofessional Education, Queen's University Dental School, Grosvenor Road, Belfast, BT12 6BP

Dr Christel McMullan, Research Fellow, Centre for Excellence in Interprofessional Education, QUB Dental School. 


\section{Introduction}

The development of effective leaders is essential for all healthcare professions and increasingly is becoming a key focus for the UK dental profession. The General Dental Council's new curriculum framework document ${ }^{1}$ places the development and demonstration of management and leadership skills as a core domain. The same is true of the dental Foundation curriculum, specialist training curricula and continuing professional development requirements. ${ }^{2-4}$ At the same time, the UK dental profession faces significant changes to working practices as the Government's policies and reforms take shape in a climate of devolutionary development. ${ }^{5-10}$ Effective leadership is considered vital in this changing context. ${ }^{5,11}$

An examination of the literature indicates that comparatively little research has been undertaken on leadership and change in the dental profession ${ }^{12-14}$ with the majority undertaken in the USA. ${ }^{13,15-16}$ At the same time, the dental profession is seen as having faced many significant changes and challenges but has lacked strong, proactive leadership which has resulted in professional disillusionment., ${ }^{11,14,17-18}$ As a consequence it has been regarded as imperative that dental professionals take ownership of their future development to radically rethink the role of dental leadership and to find a new vision and mission. ${ }^{17-20}$ Furthermore, current expectations that the future dental workforce will involve a changing skill mix, demands that dental leadership should embrace the entire dental team. ${ }^{18,20-21}$ Effective leaders are seen to be essential in moving the dental profession forward. ${ }^{14,17,24}$ 
The leadership role in the dental profession is complex and multifaceted not least in its requirement to combine business practice with patient care - a relationship with inherently conflicting tensions. ${ }^{17,23-24}$ Developing an appropriate leadership style has been advocated as a way forward. A leadership style which defines the role as servant-leader rather than self-serving leader is seen as particularly pertinent. ${ }^{25-26}$ In this model a self-serving, top-down leadership approach is replaced by the servant leader who seeks opinions and perspectives from others (patients and staff), recognizing their importance and the need to respect, value, motivate and provide a high quality service to them rather than being more concerned with the process of service delivery. A collaborative, shared leadership style ${ }^{14}$ which takes account of individual, situational, and transformational factors and encourage team decisionmaking has also been advocated as a way forward for the dental profession. The strength of both approaches is that they encourage collaborative decision-making, empower employees and create a team culture that will provide a better service for patients. ${ }^{22}$

Education has a key role in the leadership debate. Just as effective teams cannot be created without appropriate education and training, leaders also need to be educated to lead. ${ }^{11,27}$ It has been argued that the development of effective leaders, regardless of the discipline, is essentially an educational issue and that having educators and educational programmes that promote leadership skills are vital in creating effective leaders of the future. ${ }^{28-29}$ 
A recent NHS study identified undergraduate education as having a vital role to play in the development of dental leadership skills ${ }^{11}$ whilst in the USA there are already some programmes which aim to integrate leadership education at undergraduate level. ${ }^{15,30}$ There is reference to leadership skills in a European context ${ }^{31}$ but until the new GDC curriculum ${ }^{1}$ there has been little focus on management and leadership in UK undergraduate dental education. Dental academics have also identified the need for the dental profession, UK Health Departments and educators to begin to raise the profile of leadership in a teamwork culture. ${ }^{11,20}$ The study described below examines perceptions of dental leaders concerning some of these issues.

\section{Aim}

The aim of the study was to explore dental leaders' perceptions of the current position of leadership in the dental profession.

\section{Methodology}

A qualitative, key informant, exploratory research study was used with semistructured interviews as the means of data collection. Participants were identified by the research team, based on their role in dental services in the UK and their ability to act as a key informant. The criteria used to select participants included that they were professional leaders within the dental services; had a specialised knowledge of dental leadership and dental services; had knowledge of dental services policy. 
In the first instance, 12 key informants were identified and contacted by letter to invite them to take part in the study. Out of these 12 potential participants, nine agreed to take part in the study and were then sent a consent form, a more detailed overview of the study and a copy of the interview schedule. Using the same protocol as for the other participants the views of four further key professional leaders were sought to help substantiate the emergent themes. All four additional informants agreed to take part in the study.

Data were collected by means of semi-structured interviews using a topic guide to allow the interview to be guided but flexible. Each interview was conducted either at the workplace of the participant or at in a University setting and lasted between 45 and 60 minutes. The researcher conducting the interviews was not a healthcare professional and was unknown to the participants. This was considered important to allow participants to speak at ease and without hierarchical barriers. ${ }^{32}$

The interviews were audio-recorded, transcribed and analysed using NVivo 8 analysis software to assist the process of coding and the identification of the relationships between themes. ${ }^{33} \mathrm{~A}$ grounded theory ${ }^{34}$ approach was taken to provide a systematic and inductive analysis of the data and theory generation. Initially interview transcripts were categorized and coded into broad themes through an in-depth analysis. ${ }^{35}$ Following the identification of broad themes from the initial data set, when nothing new was emerging from the data four additional interviews were conducted and coded against the same framework. Themes and sub themes were 
then reviewed and refined until the final thematic headings were agreed by both members of the research team. ${ }^{36}$

Confidentiality of participants has been maintained and anonymity ensured by not attributing the quotations used to specific respondents. Approval for this research was obtained from OREC NI.

\section{Results}

The nature and number of respondents is indicated in Table 1.

Table 1: Respondents

\begin{tabular}{|l|l|l|}
\hline & $\begin{array}{l}\text { Number of key informants } \\
\text { contacted }\end{array}$ & $\begin{array}{l}\text { Number of key informants } \\
\text { who took part }\end{array}$ \\
\hline Initial request & 12 & 9 \\
\hline Additional request & 4 & 4 \\
\hline Total & $\mathbf{1 6}$ & $\mathbf{1 3}$ \\
\hline
\end{tabular}

Three broad themes emerged from the data: characteristics and behaviours of dental leaders; challenges for dental leaders; education and training for dental leadership. These themes are described below and illustrated in Figure 1.

\section{Characteristics and behaviours of dental leaders}

The key informants recognised that dentistry needed good leaders and described what was expected from a good leader in terms of characteristics and behaviours. The characteristics of a good leader included being approachable, inspiring, fair, firm, unbiased, a teamworker, a good listener, having a good knowledge of their business and having a broad perspective on key issues: 
A leader should also have good knowledge of the job they're doing, work well with the team and a good leader listens to their team and the other influences that are affecting their team and the other services that are affecting it.

It's about listening and being able to be a strong advocate for your discipline and seeing the big picture at the same time.

In relation to the behaviours of a good leader, the key informants believed that a good leader should encourage, enthuse, take decisions with confidence, have a clear vision and be able to communicate this vision to ensure clarity of purpose. They should also be an effective team leader, should bring their team forward, delegate and consult with their team and share leadership:

A good leader for me... obviously, you have to have that vision

Somebody who has a vision and can communicate this vision and can help other people catch this vision. And has the ability to take this vision forward despite whatever challenges come onboard.

This idea of shared leadership held an important place in the key informants' answers. They thought that good leadership should be about working in partnership with staff, rather than being a 'one-man team'. Good leadership should involve being able to pick the right team to work with and a good leader should encourage team members to feel confident about make decisions and taking action for the good of the team:

No good leader will do it all on their own. Any good leader that I would admire would tend to be people who get the best of the team around them by making people play to their strength and then get a unified voice, a unified sort of direction. 


\section{Challenges for dental leaders}

The key informants identified the issue of 'change' and leadership during a time of change as one of the most significant challenges for dentistry. All key informants commented on the considerable reorganisation and restructuring that had taken place in the dental service in recent years. This change was perceived as having made it difficult to achieve a unified vision for the profession. However, all the key informants identified vision and direction as necessary for successful leadership, even though difficult to achieve.

No, I don't think there is a vision, and if there is a vision it's a multiple vision, it keeps changing.

people feel like "Where are we going?", "What's the direction?" and if you haven't got a leader to show you the direction, either somebody who's leading within or the positional leader, and it's difficult to lead within if you haven't got a positional leader saying you're going in the right direction.

The restructuring of patient services was particularly challenging for those leaders dealing with patients on a day-to-day basis and the problems they faced included keeping everyone, including patients, informed of the changes and this brought about more work and stress to them as leaders as well as to other team members and patients. Many of the informants also identified the management of the public perception of these changes as a challenge for dental leaders:

That can affect morale, time of delivery and the delivery of the service and the quality of the service. It has an impact on the patients, they're our service, that's why we're here for.

The media, if they get a bad story, can make dentistry and dentists look bad. Recently there was the access problem and we saw these people queuing outside dentists and rich dentists making thousands. I think that wasn't a good image for the public. 
The reality is it's a very tough profession, it's a lonely profession, it's very stressful, it's high pressure. I don't think the public has the correct perception. Over the last couple of years, there has been a very negative perception of dentists.

The lack of funding due to the economic situation was a recurrent challenge mentioned by the key informants with several implications arising from this. First of all, the participants reported that reduction in staffing levels (e.g. through retirement or voluntary redundancies not being replaced) placed additional burdens on leaders to assure the delivery of the same level of care to the same number of patients with fewer staff:

Money. Money is our big challenge at the moment. We're not the only Trust. We're cutting back. Staff are leaving and they're not being replaced. We still have the same number of patients, we still have the same targets, but we don't have the same resources to do that.

Key informants suggested that one of the challenges faced by leaders in dentistry was around developing and growing new leaders. Many respondents indicated that there was a lack of opportunity to develop as a leader in dentistry and for some the recruitment process within the health service appeared too narrow and insular:

When those leadership roles were advertised, they were restricted to the pool of people who were already in those roles. So there was no external competition. So you are looking for new leaders from a depleted pool of people.

how do we actually grow our leaders? I think that the problem ... most of our dentists work in general dental practice, therefore they work in small isolated units. Therefore the vast bulk of our profession don't really get exposed to the opportunity to become a leader.

\section{Education and training for dental leadership}


This theme was divided into two distinct sub-themes - undergraduate, and postregistration education and training.

\section{Undergraduate education and training}

Although the key informants strongly believed that education and training in management and leadership skills should be provided at undergraduate level they also agreed that not enough (if any at all) education and training in these areas had been offered to date. There was concern that current programmes did not actually prepare participants for leadership. They recognised that some efforts had been made to teach students about teamwork and team roles but it was suggested there remained an urgent need to introduce focused and specific education for management and leadership.

I don't think there's any (training) at undergrad level, I don't think we do give undergrads any leadership training.

Education and training in dentistry is very concentrated on delivering standards. It doesn't prepare you for leadership.

the whole leadership role will have to develop in the future. It is not a major part of the curriculum and it's something we need to look at urgently.

Key informants indicated that education for leadership in the undergraduate curriculum would serve several functions. It would help further understanding of how to lead a dental practice; help educators to identify future leaders; help students to discover their own innate leadership qualities; encourage students to aspire to become dental leaders. A view was also expressed that dental students should receive leadership and management training as early as possible:

... I think right through undergraduate education, the identification of leaders for the future and giving him or her the education and training 
to develop those skills into the future, because although there are innate leaders, I'm not sure all of their resources are tapped into at all

I think there would be tremendous advantages to identifying and growing leaders early on.

\section{Post-registration education and training}

Key informants suggested that it was now commonplace to expect all dentists to be leaders and managers as well as clinicians. Many of the key informants expressed the view that there had been a lack of training for many leaders currently in that role. They specifically identified a lack of education and training for team management and leadership. In addition, most of the key informants felt that the training they had received was too generic and of little use to them. They would like to see leadership training more specific to dentistry. Some of the participants suggested that the leadership role dentists have to take on, and for which they have not been trained, could explain why some of them leave the profession:

Over the years, dentists like myself who have been trained as dentists are now expected to have managerial skills, that we were not trained for, we were not educated for.

There are some courses but not specifically for dentists, they are for other managers too, and I just wonder should the profession have more education that way, more specific to dentistry.

I think if I were to put my finger on why some dentists are very unhappy with their job and leave their job, I don't think it's because of dentistry and dealing with patients, it's the leadership role they find themselves in. 
Figure 1: Illustration of emerging themes

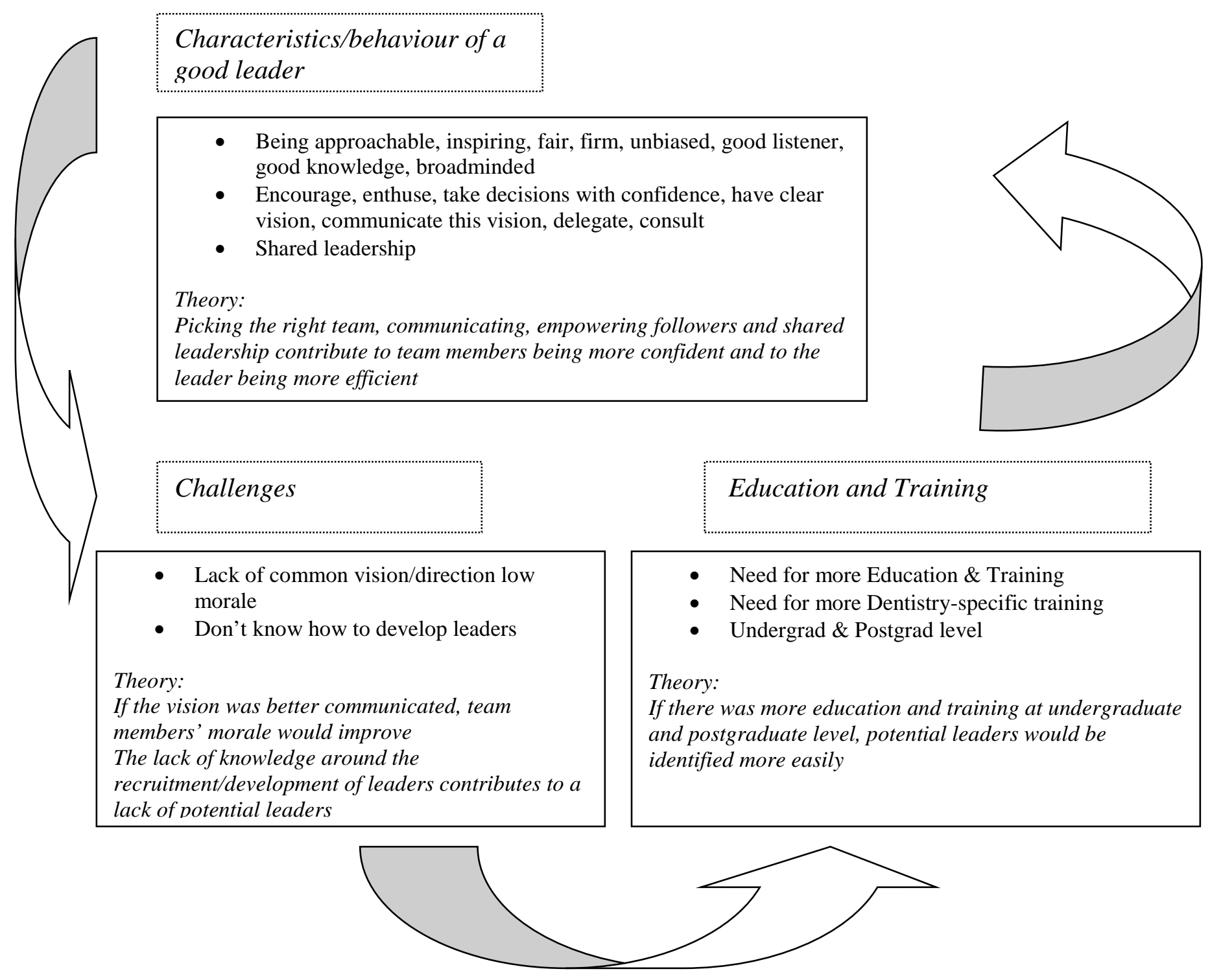

\section{Discussion}

There is comparatively little research available in this area in a UK context and the data presented here helps to begin to redress the balance and to highlight areas that need to be considered by the profession as a whole and not just its leaders.

Like all qualitative research the limitations of this study reside in the fact that data were collected from a limited number of key informants and present the aggregated 
views of the community of leaders at a specific time. Furthermore the quality of the research is dependent on the skills of the researchers. ${ }^{35-36}$ The use of a rigorous method of data collection and analysis was an important quality control. Having one member of the research team responsible for data collection and initial analysis who was unknown to the dental community (but with a background in education and management research) also helped to reduce potential bias.

The common themes which emerged from this study identify UK-wide concerns about the current and future position of leadership in the dental profession. Furthermore, the issues and concerns raised echo those from North America for example, where the dental profession is also striving to address the leadership problem. As illustrated in Figure 1, the emergent themes are inter-related and suggest a leadership cycle where essentially, effective leadership involves and is created by teamwork, communication and an appropriate programme of education.

As might be expected there was agreement that dentistry needed good leaders and the key characteristics identified by respondents are consistent with accepted theories of leadership. ${ }^{14-15}$ One noticeable emphasis was that leadership was placed in a team context and this is particularly significant given the current stress from both the dental service and dental education perspectives on skill-mix and teamwork. ${ }^{1,11,20-21}$ The notion that the profession should move towards shared leadership (consulting, involving the team in decision-making, trusting and empowering team members to act) and, it may be inferred, away from vertical 
leadership (where the leader is in charge and tells his team what to do) would seem to be appropriate in this context. The relevance of such an approach is further supported by research evidence indicating that poor performing teams are associated with vertical leadership and high performers with a shared leadership style. ${ }^{27,37}$ Alongside the recognition of a need for a shared leadership approach was the view that the dental profession needed vision and direction and this is consistent with the theories of transformational leadership. ${ }^{14}$ Ultimately there was a recognition that dental professionals will need to lead in this way in order to be effective.

The challenges for the future dental leaders were firmly perceived as being rooted in the many changes imposed upon the profession by external forces such as Government spending policies, the health service re-structure, changes in service delivery to patients and public perceptions. Further research would be needed to explore these important issues in more detail but these findings would suggest that dental leaders are recognise and are keen to seize the opportunity to determine the professions future direction.

There was agreement that education and training in leadership skills was imperative at all levels and this is consistent with views expressed in the literature. ${ }^{11,20}$ The data suggest that professionals view leadership programmes as a way of improving and shaping dentistry at all levels. Indeed, a lack of training for the leadership role dentists have to take on at all levels and throughout the profession, was identified as 
a key factor in dentists leaving the profession. It would therefore seem that more training in management and leadership could help prevent this loss of skill and experience within the profession.

The launch of the new team-based GDC curriculum ${ }^{1}$ which includes a Management and Leadership domain for all dental and related professions should provide an ideal opportunity for education-based dental leaders to develop programmes that will nurture future leaders and kick-start a new approach to leadership in the dental profession and there are examples already in the USA ${ }^{15,37}$ from which they can learn. Such programmes should also help to deal with the potential shortages in qualified leaders in dental schools and help future dentists to deal effectively with everyday challenges occurring in a dental practice. In tandem with this will be a requirement for research to measure the impact of these programmes at UK and international levels, on the students' leadership competencies over time and the extent to which students become involved in leadership role throughout their career.

\section{Conclusion}

Leadership is a vital issue for a dental profession in a changing environment and current leaders are aware of the need for a leadership style that embraces the team work ethos and reflects the changing skill mix in the workforce. Whilst recognising that a lack of focus on management and leadership skills has caused problems in the past, current dental leaders are prepared to lead the profession forward and view education at all levels as vital to this process. Although presently noticeable by its 
absence from most undergraduate programmes, dental leaders view education for leadership at this early stage as an important way forward. The new GDC curriculum provides a framework to encourage and support this but additional research is required to explore this further and provide evidence to support future development.

\section{References}

1. General Dental Council. Preparing for Practice. Dental team learning outcomes for registration. London: GDC 2011

2. Committee of Postgraduate Dental Deans and Directors. A Curriculum for UK Dental Foundation Programme Training. London: COPDEND 2006.

3. Committee of Postgraduate Dental Deans and Directors. The dental gold guide. A Reference Guide For Postgraduate Dental Specialty Training In The UK. Second edition. London: COPDEND 2011.

4. General Dental Council. Continuing Professional Development (CPD) for dentists. London: GDC 2009.

5. Steele J. NHS Dental Services in England. An independent review led by Professor Jimmy Steele. London: Department of Health 2009.

6. Department of Health, Social Services and Public Safety. Review of Public Administration. Available at: http://www.dhsspsni.gov.uk/index/hss/rpa-home.htm 7. NHS Wales. Routes to reform: A strategy for Primary Dental Care in Wales 2002. Available at: http://www.wales.nhs.uk/documents/dent-strat-e.pdf, accessed $27 / 02 / 12$. 
8. NHS Wales. Plans to improve Dental Care in Wales 2010. Available at:

http://www.wales.nhs.uk/documents/W100900-Hlt.pdf, accessed 27/02/12.

9. Scottish Executive. An action plan for improving oral health and modernizing NHS dental services in Scotland 2005. Available at:

http://www.scotland.gov.uk/Resource/Doc/37428/0012526.pdf, accessed 27/02/12

10. Scottish Government. Better Health, Better Care Action Plan 2007. Available at www.scotland.gov.uk/publications/2007

11. National Clinical Assessment Service. Factors influencing dental practitioner performance: a literature review. London: NCAS 2011

12. Dancer J, and Taylor C. Dentistry is different: practitioner perceptions of the business of dentistry. Clinician in Management 2007; 15: 11-27.

13. Seaman C. Leadership in Dentistry: an empirical phenomenological study of practicing general dentists in South Idaho, unpublished thesis 2008.

14. Willcocks S. Leadership theory: implications for developing dental surgeons in primary care. Brit Den J 2011; 201: 105-107

15. Victoroff KZ, SchneiderK, Perry C. Leadership development for dental students: what do students think? J. Dent Educ 2008; 72: 982-988

16 Levin R. The dentist as leader. J Am Dent Assoc 2003; 134:1391-1392

17. Holt VP. The need for Leadership and Vision in Dentistry. A Personal View.

Primary Dental Care 2008; 15: 113-119.

18. Cottingham J, and Toy A. The Industrialisation of the dental profession, Brit Den J 2008; 206: 347-350. 
19. Roth K. Dental Education: A Leadership Challenge for Dental Educators and Practitioners. J Dent Ed 2007; 71: 983-987.

20. Gallagher J, Wilson N. The future dental workforce? Br Dent J. 2009; 206:195199.

21. Brocklehurst $P$, Tickle $M$. The policy context for skill mix in the National Health Service in the United Kingdom. Brit Dent J 2011; 211:265-269

22. Chilcutt A, Exploring leadership and team communication within the organizational environment of a dental practice. J Am Dent Assoc 2009; 140:12521258.

23. Welie JV. Is Dentistry a Profession? Journal of the Canadian Dental Association 2004; 70: 529-532.

24. Trathen A, and Gallagher J. Dental Professsionalism: definitions and debate. $\mathrm{Br}$ Dent J 2009; 206: 249-253.

25. Certosimo F. The Servant Leader: A Higher Calling for Dental professionals. J Dent Educ 2009; 73: 1065-1068.

26. Certosimo F. Leaders or Managers: Who will define a new vision for dental education? J Dent Educ 2010; 74: 459-463.

27. Morison S, and Stewart M. Developing effective teams and protecting the vulnerable: an interprofessional journey. In Carettas K. (ed) Outsourcing, Team Work and Business Management. (pp99-113) New York: Nova Science Publishers Inc 2009. 28. Simpson J, and Calman K. Making and preparing leaders. Med Educ 2000; 34: 211-5. 
29. Parsell G, and Bligh J. Encouraging educational leadership. Med Educ 2000; 34: 199-200.

30. Kalenderian E, Skoulas A, Timothe P, Friedland B. Integrating leadership into a practice management curriculum for dental students. J Dent Educ 2010; 74: 464-471 31. Cowpe J, Plasschaert A, Harzer W, Vinkka-Puhakka H, and Walmsley D. Profile and competences for the graduating European dentist - update 2009. Euro J Dent Educ 2010; 14: 193-202.

32. Puchta C, and Potter J. Focus group practice. London: Sage Publications 2004.

33. Lewins A, and Silver C. Using Software in qualitative research. London: Sage Publications 2007.

34. Strauss A, and Corbin J. Basics of qualitative research: Grounded theory procedures and techniques. Newbury Park, CA: Sage Publications 1990.

35. Burnard P, Gill P, Stewart K, Treasure E and Chadwick B. Analysing and presenting qualitative data. BDJ 2008; 204:429-432.

36. Pope C, Ziebland S, Mays N. Analysing qualitative data. BMJ 2000; 320:114-116 37. Pearce $C$. The future of leadership: combining vertical and shared leadership to transform knowledge at work. Academy of management executive 2004; 18: 47-57 